\title{
Human rhinovirus infection during naturally occurring COPD exacerbations
}

\author{
Sîobhán N. George, Davinder S. Garcha, Alexander J. Mackay, \\ Anant R.C. Patel, Richa Singh, Raymond J. Sapsford, Gavin C. Donaldson and \\ Jadwiga A. Wedzicha
}

Affiliations: Centre for Respiratory Medicine, University College London, London, UK.

Correspondence: Sîobhán N. George, University College London, Rowland Hill Street, Hampstead, London, NW3 2PF, UK. E-mail: siobhan.george.10Aucl.ac.uk

ABSTRACT Human rhinovirus (HRV) infection is an important trigger of exacerbations of chronic obstructive pulmonary disease (COPD) but its role in determining exacerbation frequency phenotype or the time-course of HRV infection in naturally occurring exacerbations is unknown.

Sputum samples from 77 patients were analysed by real-time quantitative PCR for both HRV (388 samples), and Streptococcus pneumoniae, Haemophilus influenzae and Moraxella catarrhalis (89 samples). Patients recorded worsening of respiratory symptoms on daily diary cards, from which exacerbations were identified.

HRV prevalence and load at exacerbation presentation were significantly higher than in the stable state (prevalence $53.3 \%$ versus $17.2 \%$, respectively; $\mathrm{p}<0.001$ ) but $0 \%$ by day 35 post-exacerbation. HRV load was higher in patients with cold symptoms $(p=0.046)$ or sore throats $(p=0.006)$ than those without. $73 \%$ of bacterium-negative but HRV-positive exacerbations were bacterium-positive by day 14. Patients with HRV detected at exacerbation had a higher exacerbation frequency (interquartile range) of 3.01 (2.02-5.30) per year compared with patients without HRV (2.51 (2.00-3.51)) $(\mathrm{p}=0.038)$.

HRV prevalence and load increased at COPD exacerbation, and resolved during recovery. Frequent exacerbators were more likely to experience HRV infection. Secondary bacterial infection is common after HRV infection, and provides a possible mechanism for exacerbation recurrence and a potential target for novel therapies.

@ERSpublications

Increased HRV prevalence and load are aetiological factors in natural COPD exacerbations and frequent exacerbations http://ow.ly/tlscz

For editorial comments see page 11.

This article has supplementary material available from www.erj.ersjournals.com

Received: Dec 202013 | Accepted after revision: Jan 282014 | First published online: March 132014

Support statement: This study was funded by the Medical Research Council Patient Cohort Research Initiative G0800570/1.

Conflict of interest: Disclosures can be found alongside the online version of this article at www.erj.ersjournals.com

Copyright @ERS 2014 


\section{Introduction}

Chronic obstructive pulmonary disease (COPD) is the third leading cause of death worldwide [1]. It is an inflammatory condition caused by an abnormal response to particles and noxious gases, mainly cigarette smoke, in patients with a susceptible genetic background [2]. Episodes of worsening respiratory symptoms are termed acute exacerbations of COPD. These events are a leading cause of hospital admissions [3], and are associated with impaired quality of life [4], large healthcare costs [5], faster lung function decline [6] and higher mortality [7].

Respiratory infections, such as bacteria, viruses or co-infection with both, have been shown to be an important feature of COPD exacerbation onset, with viruses being detected in two-thirds of exacerbations [8]. Viral infections are associated with more severe exacerbations in terms of symptoms, resulting in longer recovery times and greater likelihood of hospitalisation [9]. Human rhinovirus (HRV) is one of the causes of the common cold and is the major viral pathogen detected in COPD exacerbation [10], having been identified in up to $60 \%$ of virus-associated exacerbations using quantitative PCR (qPCR) [8]. It has been shown that experimental HRV infection triggers COPD exacerbations [11], although these episodes were mild events that did not require increased systemic therapy.

COPD exacerbations are complex events that can last for prolonged periods of time. There is little information on the course of HRV infection during and after naturally occurring COPD exacerbations. This is surprising, given that HRV infection is an important trigger of exacerbations and that exacerbations are known to be important events in the natural history of the disease. Information on HRV presence and load during the onset and recovery of an exacerbation may allow appropriate targeting of therapeutic interventions, and thus help reduce exacerbation severity. Furthermore, we examined the relationship of HRV infection with upper airway symptoms, secondary bacterial infection and patient-recorded outcomes to further expand our knowledge of HRV infection in COPD exacerbation. Some COPD patients are especially prone to developing exacerbations and the mechanisms underlying this susceptibility are still unknown [4].

To date, changes in HRV load over the time-course of naturally occurring COPD exacerbations and the recovery period have not been investigated. We hypothesised that HRV prevalence and load would increase during naturally occurring COPD exacerbations, and that HRV infection would be associated with greater symptoms and the development of secondary bacterial infection. For the first time, this study explored changes in the prevalence and load of HRV in COPD patients using GPCR in the stable state, during naturally occurring COPD exacerbations and recovery. We also analysed the association of upper airway symptoms and bacterial infection with changes in HRV load.

\section{Methods}

\section{Patient recruitment}

The patients involved in study were all participants in the London COPD Cohort, which is a prospective study of COPD exacerbations. The 77 patients studied had all presented with one or more acute COPD exacerbations between January 2008 and December 2011. They had a post-bronchodilator forced expiratory volume in $1 \mathrm{~s}(\mathrm{FEV} 1)<80 \%$ of a normal value predicted from age, height and sex, and FEV1/forced vital capacity (FVC) ratio of $<0.7[4,12]$. Patients with a history of any other significant respiratory diseases and those unable to complete daily diary cards were excluded.

Patients were routinely seen at the research clinic every 3-6 months for sampling of sputum. These visits were defined as stable-state visits providing there had been no exacerbation onset in the 4 weeks before or during the 2-week interval after. Once a year, patients underwent a comprehensive review where FEV1 and FVC were measured with a Vitalograph Gold Standard spirometer (Vitalograph Ltd, Maids Moreton, UK) and a history was taken of smoking habits (years of smoking and current smoking status).

\section{Definition of exacerbation and exacerbation sampling}

All patients were asked to record on daily diary cards any increases in major respiratory symptoms (dyspnoea, sputum purulence or sputum volume) or minor respiratory symptoms (cold defined as nasal discharge/congestion, wheeze, sore throat or cough). This daily recording of symptoms was used to precisely define the onset and recovery of exacerbations as described below. As in our previous work, exacerbation onset was defined as the first of $\geqslant 2$ days in which the patient recorded two or more new or worsening symptoms, one of which must have been a major symptom. Symptoms were disregarded in identifying exacerbation onset if recorded continuously in the 5-day period preceding suspected exacerbation onset. Some exacerbations were identified in the absence of any diary card data, if the patient had been admitted to hospital for an exacerbation or had seen another physician outside the study (e.g. if a patient had been on holiday, and been prescribed antibiotics and/or oral corticosteroids). 
FIGURE 1 Chronic obstructive pulmonary disease patient groups analysed. Patient samples may have been included in more than one subanalysis. EXACT: Exacerbations of Chronic Pulmonary Disease Tool.

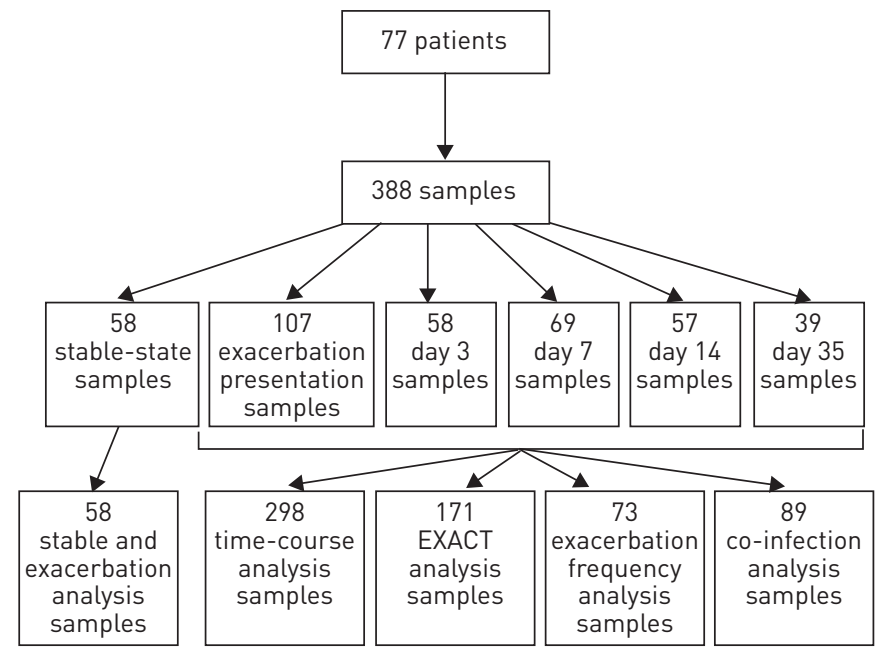

Patients were strongly encouraged to contact the study team via a dedicated telephone line when they experienced any increase in their daily respiratory symptoms. They were seen within $48 \mathrm{~h}$ by a physician from the study team, their symptoms were reviewed and the exacerbation was confirmed according to our symptomatic definition above. Spontaneously expectorated sputum was collected in a sterile container from COPD patients. Sputum was collected in the stable state, at exacerbation presentation (ExP), and during recovery at days $3,7,14$ and 35 post-ExP. The median time between the onset of the exacerbation and the sample was 3 days. Figure 1 illustrates which patient samples were included in each analysis. Processing methods can be found in the online supplementary material. Exacerbations were treated according to the prevailing guidelines and clinical judgment with increased inhaled therapy, antibiotics and/or oral steroids.

\section{Exacerbation frequency}

An annual exacerbation rate was calculated for each patient by dividing the number of exacerbations a patient experienced by the number of years of diary card data in 2011 and 2012. This time period was chosen as it was contemporaneous with $90 \%$ of the samples. Patients with $<1$ year of diary card data were given an exacerbation rate equal to the number of events recalled in the previous year. Previous work has shown a good correlation between the number of exacerbations recorded on diary cards and the number of exacerbations recalled by the patient over the same 1-year period [12] and it has been shown that exacerbation frequency represents a relatively stable patient phenotype [13].

\section{Exacerbations of Chronic Pulmonary Disease Tool}

Permission to use the Exacerbations of Chronic Pulmonary Disease Tool (EXACT) questionnaire to score symptom intensity was obtained from United BioSource Company (Bethesda, MD, USA). Patients completed a paper version of the EXACT at least once under supervision in the clinic and then at home, based on their symptoms experienced on the day of completion. Patients prospectively completed the EXACT on a daily basis when stable and continued long-term to enable capture of the EXACT score at exacerbation.

\section{RNA extraction and reverse transcription}

RNA was extracted from homogenised sputum samples using the TRI reagent LS (Molecular Research Center Inc., Cincinnati, OH, USA) method [14]; details can be found in the online supplementary material. cDNA was prepared using the High-Capacity cDNA Reverse Transcription Kit (Applied Biosystems, Carlsbad, CA, USA).

\section{qPCR detection of HRV and typical bacteria}

Thermocycling and real-time detection of qPCR products were performed using the ABI Prism 7500 Realtime qPCR System (Applied Biosystems). All the qPCR samples were run in duplicate and the correlation in the $\mathrm{qPCR}$ results between the two runs was $\mathrm{r}=0.991$ (online supplementary fig. E1). Details of primers and probes for HRV qPCR are shown in table E1.

DNA extraction and multiplex qPCR detection of typical bacteria have been previously described by our group [15]. 


\section{Statistical analysis}

Data were analysed using PASW Statistics v.19 (IBM Corporation, New York, NY, USA). The KolmogorovSmirnov test for normality was applied. Absolute HRV loads were reported as median (interquartile range $(\mathrm{IQR})$ ). For graphical illustrations, $\log _{10}$-transformed data were presented as mean \pm SEM. Nonparametric data were analysed using Mann-Whitney U-tests and Wilcoxon tests for unpaired and paired data, respectively. Relationships between continuous variables were analysed using Spearman's rank correlation in a univariate analysis. A probability value of $\mathrm{p}<0.05$ was considered to be statistically significant.

Exacerbations were considered as separate events when describing HRV time-course because their trigger (viral or bacterial) could differ within the same individual. In other analysis, where HRV infection was related to patient characteristics, only the first exacerbation sample was used from each patient to avoid complications with repeated measures.

\section{Ethical approval}

This study was approved by the Royal Free Research Ethics Committee at the Royal Free NHS Trust (London, UK) where this work was under-taken $(09 / \mathrm{H} 0270 / 8)$. All patients involved in the study gave informed, written consent.

\section{Results}

\section{Patient characteristics}

77 patients from the London COPD Cohort provided sputum samples for this study (fig. 1). Their baseline physiological characteristics are reported in table 1 . These patients experienced 107 exacerbations, of which $89 \%$ were treated with antibiotics and $81 \%$ with oral steroids, and $2 \%$ led to hospitalisation.

\section{Rhinovirus prevalence and load}

There was a significantly higher prevalence of HRV at exacerbation (57 out of 107, 53.3\%) compared with the stable state $(10$ out of $58,17.2 \%)(p<0.001)$ (fig. $2 \mathrm{a})$. In unpaired samples positive for HRV, the mean \pm SEM HRV load increased significantly from the stable state $\left(2.11 \pm 0.3 \log _{10}\right.$-transformed plaqueforming units (pfu) per $\mathrm{mL}$ ) to exacerbation $\left(3.27 \pm 0.2 \log _{10} \mathrm{pfu} \cdot \mathrm{mL}^{-1}\right)(\mathrm{p}=0.004)$ (a 15 -fold increase in absolute terms) (fig. 2b). In a smaller but paired subset of 49 exacerbation and stable state samples, the mean HRV load was also significantly higher at exacerbation $\left(2.16 \pm 0.3 \log _{10} \mathrm{pfu} \cdot \mathrm{mL}^{-1}\right)$ compared with the stable state $\left(0.40 \pm 0.2 \log _{10} \mathrm{pfu} \cdot \mathrm{mL}^{-1}\right)(\mathrm{p}<0.001)$. There was no significance difference in the median number of days between the onset and date of sampling in exacerbations with or without HRV present: 3 versus 4 days, respectively $(\mathrm{p}=0.336)$.

Of the 57 HRV-positive exacerbation samples, 21 exacerbations had cold symptoms with a mean HRV load of $3.93 \pm 0.4 \log _{10} \mathrm{pfu} \cdot \mathrm{mL}^{-1}$. This was significantly higher than in exacerbations without cold symptoms $\left(\mathrm{n}=36 ; 2.88 \pm 0.2 \log _{10} \mathrm{pfu} \cdot \mathrm{mL}^{-1}, \mathrm{p}=0.046\right)$ (fig. 3a). Mean HRV load was higher when a sore throat was reported $\left(\mathrm{n}=22 ; 4.12 \pm 0.4 \log _{10} \mathrm{pfu} \cdot \mathrm{mL}^{-1}\right)$ than without a sore throat $\left(\mathrm{n}=35 ; 2.73 \pm 0.2 \log _{10} \mathrm{pfu} \cdot \mathrm{mL}^{-1}\right)$ $(\mathrm{p}=0.006)$ (fig. $3 \mathrm{~b})$. The number of HRV-negative exacerbations $(\mathrm{n}=50)$ that had cold symptoms was $19(38 \%), 11(22 \%)$ had a sore throat and two (4\%) had both symptoms.

\section{HRV infection at exacerbation and exacerbation frequency}

Patients positive for HRV $(n=42)$, during their first sampled exacerbation, had a significantly higher exacerbation frequency than those patients in whom HRV was not detected $(n=31)$; data on exacerbation frequency were missing for four patients who could not recall how many exacerbations they had

TABLE 1 Clinical characteristics of 77 chronic obstructive pulmonary disease patients sampled in this study

$\begin{array}{lc}\text { FEV } 1 \text { L } & 1.12 \pm 0.5 \\ \text { FVC L } & 2.25 \pm 0.9 \\ \text { FEV1/FVC \% } & 46.2 \pm 14.9 \\ \text { FEV } 1 \text { \% predicted } & 44.9 \pm 20.3 \\ \text { Treated with ICS } & 86 \\ \text { Current smokers } & 35 \\ \text { Age years } & 70.6 \pm 8.0 \\ \text { Males } & 61\end{array}$

Data are presented as mean \pm SD or \%. FEV1: forced expiratory volume in $1 \mathrm{~s}$; FVC: forced vital capacity; ICS: inhaled corticosteroid. 

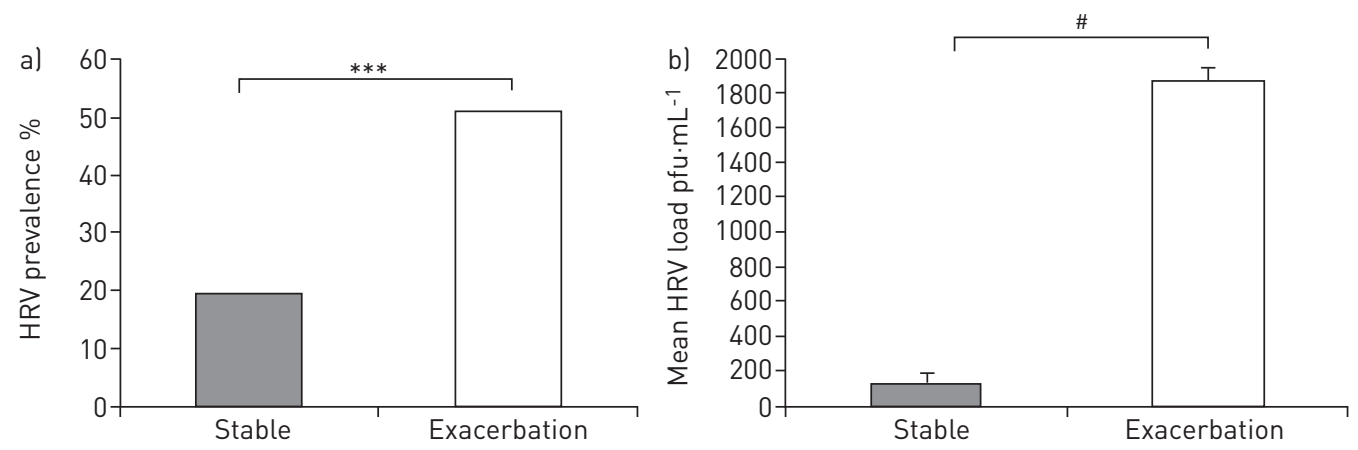

FIGURE 2 Quantitative PCR comparison of a) prevalence of human rhinovirus (HRV) in stable chronic obstructive pulmonary disease (COPD) $(n=58)$ and at exacerbation $(n=107)$, and of b) HRV load in stable COPD $(n=10)$ and at exacerbation $(\mathrm{n}=57)$ in HRV-positive samples. Data are presented as mean \pm SEM. pfu: plaque-forming unit. ${ }^{* * *}: \mathrm{p}<0.001 .{ }^{*}: \mathrm{p}=0.004$.

experienced in the previous year. The median (IQR) number of exacerbations per year were 3.01 (2.02-5.30) versus $2.51(2.00-3.51)$, respectively $(\mathrm{p}=0.038)$ (fig. $4 \mathrm{a})$. In addition, HRV load at ExP was related to the annual rate of exacerbations $(r=0.265, p=0.024)$ (fig. $4 b)$.

\section{HRV load and EXACT scores}

At different time points during exacerbation and recovery, 41 patients recorded EXACT scores on the same day as 171 sputum samples were collected. Those patients infected with HRV at the time of sampling $(n=58)$ had a mean EXACT score of $48.5 \pm 1.5$ compared with $45.1 \pm 0.9$ for those not infected $(n=113$; $\mathrm{p}=0.046)$ (fig. 5a). Higher HRV loads were also positively correlated with the EXACT score $(r=0.180$, $\mathrm{p}=0.019$ ) (fig. 5b).

\section{HRV load during COPD exacerbation recovery}

Figure 1 shows that 53 patients provided a total of 298 sputum samples during 78 exacerbations; 75 were taken at ExP, 58 on day 3 post-ExP, 69 on day 7, 57 on day 14 and 39 on day 35.

HRV prevalence fell from $60 \%$ at $\operatorname{ExP}$ to $44.8 \%$ at day 3, 20.3\% at day 7, $15.8 \%$ at day 14 and $0 \%$ at day 35; significant falls in prevalence from ExP were seen at day 7, 14 and 35 (all p<0.001) (fig. E2A). In the exacerbations positive for HRV at ExP, the median (IQR) HRV load decreased significantly from ExP (2.72 (1.6-4.8) $\left.\log _{10} \mathrm{pfu} \cdot \mathrm{mL}^{-1}\right)$ to day $3\left(1.34(0-2.7) \log _{10} \mathrm{pfu} \cdot \mathrm{mL}^{-1}\right)(\mathrm{p}=0.010$; paired data, $\mathrm{n}=43)$ and then to day $7\left(0(0-1.4) \log _{10} \mathrm{pfu} \cdot \mathrm{mL}^{-1}\right)(\mathrm{p}=0.023)$. There was also a significant decrease in load from day 14 $\left(0(0-0) \log _{10} \mathrm{pfu} \cdot \mathrm{mL}^{-1}\right)$ to day $35\left(0(0-0) \log _{10} \mathrm{pfu} \cdot \mathrm{mL}^{-1}\right)(\mathrm{p}=0.033)$ (fig. E2B).

There was no difference in the prevalence or load of HRV in exacerbations treated with antibiotics and/or oral steroids at any of the time points.

HRV load and upper respiratory tract symptoms

The median HRV load was significantly higher in patients who reported cold symptoms at ExP $(n=29)$ compared with those who did not $(\mathrm{n}=14)$ (3.77 (1.79-5.05) versus 1.79 (1.39-2.69) $\log _{10} \mathrm{pfu} \cdot \mathrm{mL}^{-1}$,
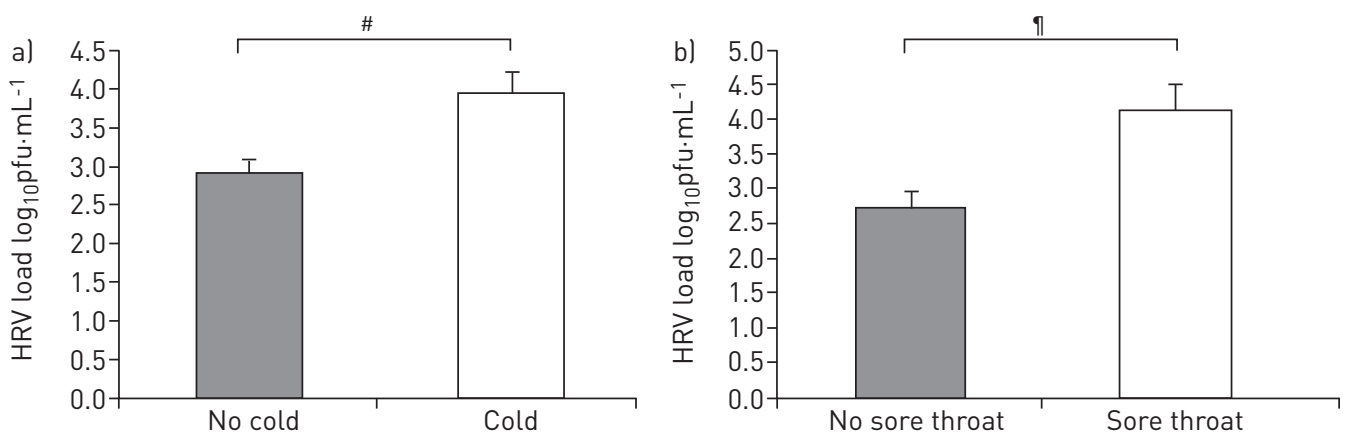

FIGURE 3 Quantitative PCR comparison of load of human rhinovirus (HRV) in patients with a) cold symptoms ( $\mathrm{n}=21$ ) and patients with no cold symptoms $(n=36)$ at exacerbation, and b) patients with a sore throat $(n=22)$ and patients with no sore throat $(n=35)$ at exacerbation. pfu: plaque-forming unit. ${ }^{\#}: p=0.046 ;{ }^{\natural}: p=0.006$. 

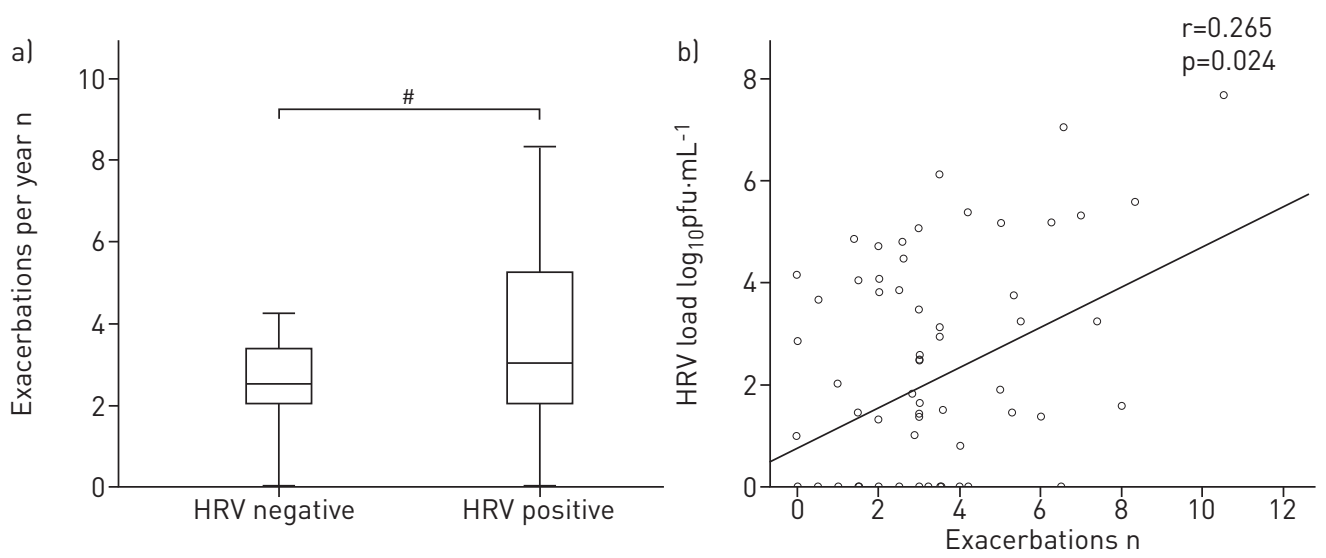

FIGURE 4 a) The number of exacerbations per year in patients with human rhinovirus (HRV) $(n=42)$ was significantly higher than in those without HRV $(n=31)$. Horizontal lines represent the median, boxes represent the interquartile range and whiskers represent the range. b) There was an association between the number of exacerbations had by patients per year and the HRV load. pfu: plaque-forming unit. ${ }^{\#}: p=0.038$.

respectively) ( $p=0.006$ ) (fig. 6a). In both groups, the HRV load fell over the recovery period, being highest at $\operatorname{ExP}$ and zero at day 35. In exacerbations with cold symptoms, there was a significant fall in the median HRV load from $\operatorname{ExP}\left(3.77(1.79-5.05) \log _{10} \mathrm{pfu} \cdot \mathrm{mL}^{-1}\right)$ to day $3\left(1.94(0-3.61) \log _{10} \mathrm{pfu} \cdot \mathrm{mL}^{-1}\right)(\mathrm{p}<0.001)$, although there was no significant change between these time points in HRV load in patients without cold symptoms $(p=0.517)$. In patients who reported a sore throat, the median HRV load was higher at each time point compared to those without a sore throat (fig. 6b). At ExP, the load was significantly higher in the group of patients that reported a sore throat, $3.38(2.43-4.99) \log _{10} \mathrm{pfu} \cdot \mathrm{mL}^{-1}$ compared with those that did not $\left(1.67(1.38-3.19) \log _{10} \mathrm{pfu} \cdot \mathrm{mL}^{-1}\right)(\mathrm{p}=0.039)$. Significant differences were also seen at days 3 and 7 but not days 14 or 35 .

\section{HRV infection and secondary bacterial infection at COPD exacerbation}

Of the 78 time-courses, 45 were HRV-positive at ExP. Of these, sufficient sputum was available for bacterial qPCR in 21 time-courses provided by 19 patients, a total of 89 samples.

In exacerbations negative for typical airway bacteria at $\operatorname{ExP}(n=11)$, the median bacterial load increased significantly from zero to 7.0 (3.3-7.6) $\log _{10}$-transformed colony-forming units (cfu) per mL by day 14 $(\mathrm{p}=0.002)$ with eight $(73 \%)$ out of 11 bacterium-negative samples becoming positive for bacteria by day 14 . In these 11 exacerbations, HRV load fell significantly from $\operatorname{ExP}\left(2.7(1.5-4.9) \log _{10} \mathrm{pfu} \cdot \mathrm{mL}^{-1}\right)$ to 0 by day 35 $(\mathrm{p}<0.001)$ (fig. $7 \mathrm{a})$.

In exacerbations positive for typical airway bacteria at $\operatorname{ExP}(n=10)$, the median load decreased significantly from $6.7(5.7-8.5) \log _{10} \mathrm{cfu} \cdot \mathrm{mL}^{-1}$ to $0(0-4.4) \log _{10} \mathrm{cfu} \cdot \mathrm{mL}^{-1}$ on day $7(\mathrm{p}=0.004)$. The load rose between day $7\left(0(0-4.4) \log _{10} \mathrm{cfu} \cdot \mathrm{mL}^{-1}\right)$ and day $14\left(5.43(0-7.0) \log _{10} \mathrm{cfu} \cdot \mathrm{mL}^{-1}\right)$ although this change did not reach
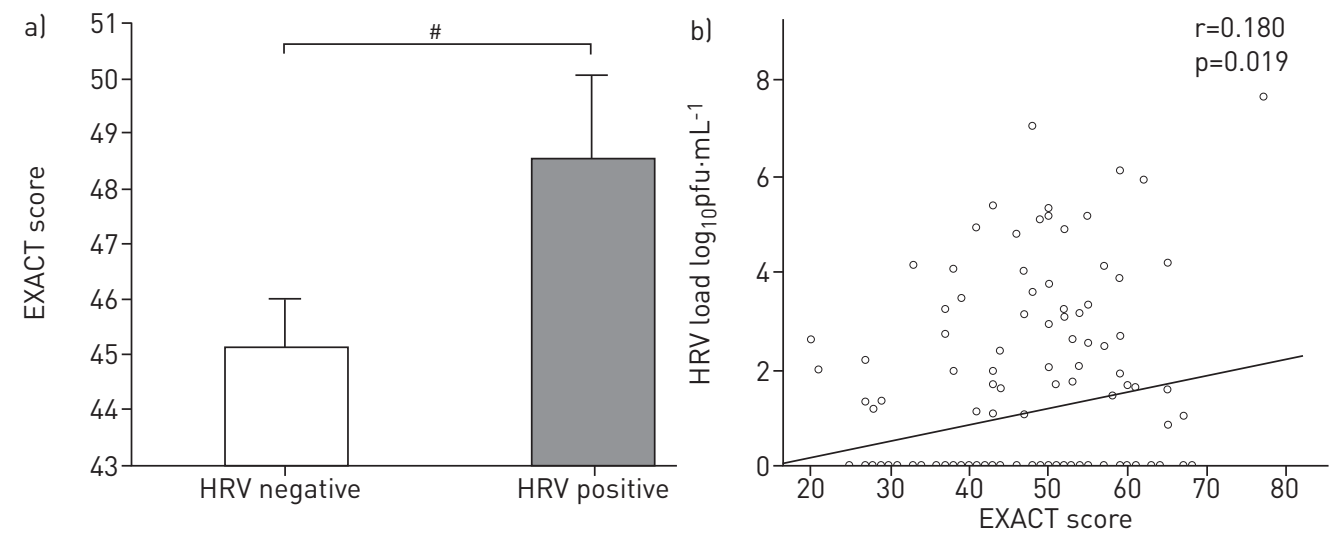

FIGURE 5 a) Patients infected with human rhinovirus (HRV) ( $=58)$ had higher Exacerbations of Chronic Pulmonary Disease Tool (EXACT) scores than those without HRV $(n=113)$. Data are presented as mean \pm SEM. b) A correlation was found between the HRV load and the EXACT score. pfu: plaque-forming units. ${ }^{\#}: \mathrm{p}=0.046$. 

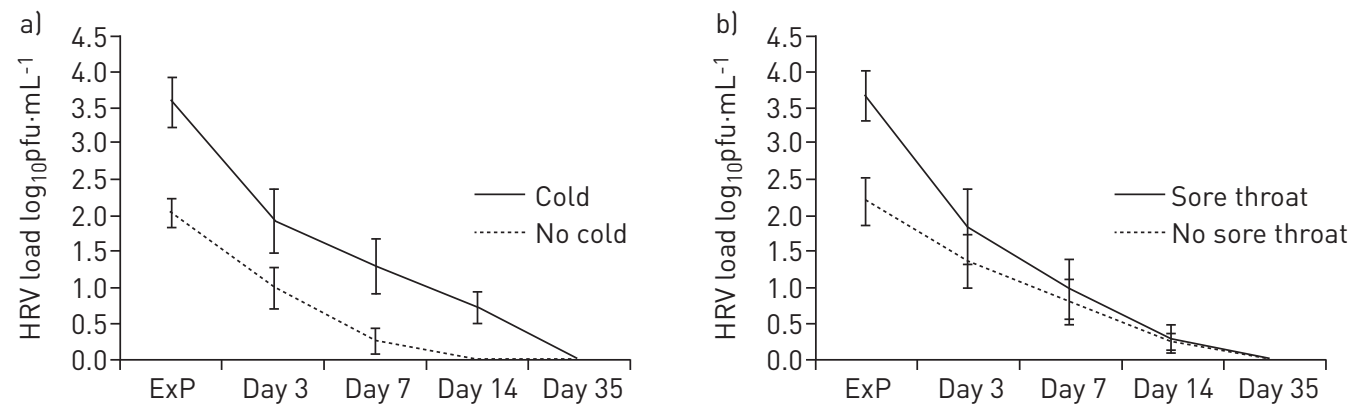

FIGURE 6 Change in the load of human rhinovirus (HRV) during the time-course of exacerbation recovery in patients with a) cold symptoms $(\mathrm{n}=88)$ and patients without cold symptoms $(\mathrm{n}=76)$ using quantitative PCR and with $\mathrm{b})$ a sore throat $(n=65)$ and patients without a sore throat $(n=99)$. Data are presented as mean \pm SEM. ExP: exacerbation presentation; pfu: plaque-forming units.

statistical significance. With respect to HRV, the median HRV load fell significantly from ExP (2.4 (1.3-3.2) $\left.\log _{10} \mathrm{pfu} \cdot \mathrm{mL}^{-1}\right)$ to 0 by day $35(\mathrm{p}=0.001)$ (fig. $\left.7 \mathrm{~b}\right)$. There was no significant difference in the HRV load at ExP between the two groups (fig. 7).

For all 21 exacerbations, at day 14, when bacterial load peaked, 36\% of patients reported dyspnoea, $18.2 \%$ had a change in sputum purulence, $54.5 \%$ had an increase in sputum volume, $9.1 \%$ reported cold symptoms and $36.4 \%$ reported a cough. When dividing the bacteriology data by species, the number of positive samples was low and so no significant conclusions could be drawn. The results are shown in table E2.

$66(86 \%)$ patients were on inhaled corticosteroid (ICS) treatment at exacerbation presentation. There were no differences in the prevalence of either HRV or bacteria in patients with or without ICS. Similarly, there was no difference in the HRV or bacterial load in patients with or without at ICS at any of the time points (tables E5 and E6). All 21 exacerbations that were tested for bacteria were treated with antibiotics whether they were subsequently found to be positive or negative for typical bacteria at exacerbation presentation. All exacerbations were treated with antibiotics for 7 days, apart from two, which were treated for 10 days, one of which was bacterium-negative and one of which was bacterium-positive.

\section{Discussion}

This is the first study to investigate the role of HRV infection using viral load measurements during the complete time-course of naturally occurring COPD exacerbations. We explored the relationship of HRV infection with upper airway symptoms and clinical parameters such as exacerbation frequency. We found a significant increase in the prevalence and load of HRV at exacerbation compared with the stable state. The HRV load was significantly higher in patients who reported upper airway symptoms compared with those who did not and, importantly, in patients with a higher exacerbation frequency. For the first time, we have studied the effect of HRV infection using the EXACT questionnaire, a validated patient-reported exacerbation outcome [16], and shown a relationship between HRV infection and higher EXACT scores. Additionally, we have investigated the time-course of airway bacterial load after natural HRV infection in
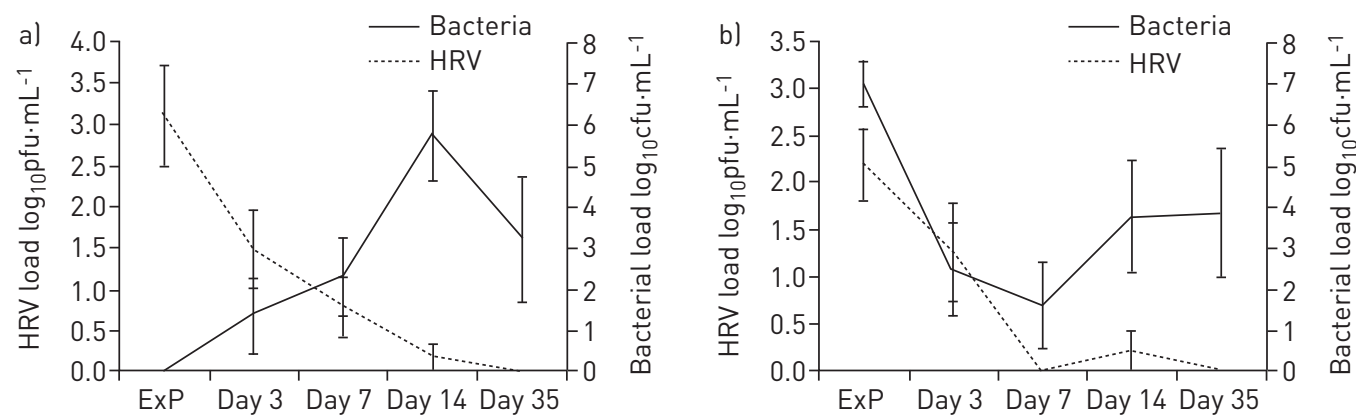

FIGURE 7 Changes in the load of human rhinovirus (HRV) and typical bacterial during chronic obstructive pulmonary disease exacerbation and recovery a) in patients negative for bacteria $(n=11)$ at exacerbation presentation $($ ExP $)$ and $b)$ in patients positive for bacteria $(n=10)$ at ExP. Data are presented as mean \pm sEM. pfu: plaque-forming units; cfu: colonyforming units. 
COPD patients, and shown a relationship between initial HRV infection and secondary bacterial infection at COPD exacerbation.

HRV has been shown to be associated with exacerbations both in asthma [17] and COPD [8]. In this study, we found that the prevalence of HRV in sputum was greater at exacerbation $(53.3 \%)$ than in the stable state (17.2\%) and this is consistent with previous data [9]. Similarly, HRV load, measured by qPCR, was significantly higher at exacerbation compared with in the stable state, with a 15-fold increase in absolute terms.

HRV infection is the most common cause of the upper airway cold and at exacerbation; patients with cold symptoms had significantly higher HRV loads than those without. A study of experimental HRV infection in asthmatics found a similar relationship between HRV load and cold symptoms [18]. In a study of experimental HRV infection in COPD patients, HRV load was shown to peak at day 5 post-inoculation, with cold symptoms peaking at day 3 [11]. Thus, our results confirm the association of upper airway symptoms and HRV infection, and, importantly, emphasise that the presence of HRV may be indicated by the presence of cold symptoms. It also highlights the importance of early sampling of COPD patients at exacerbation in order to study their pathophysiology. A unique advantage of the London COPD Cohort is that we prospectively follow our patients, reviewing them with exacerbation symptoms early after onset, optimising viral detection and enabling study of the time-course of these events.

Some patients with COPD are particularly susceptible to exacerbations and are termed "frequent exacerbators" [19]. Our previous work has suggested that these patients are more likely to develop colds [19] and in this study we detected HRV infection more commonly in frequent exacerbators. For the first time, we have demonstrated a weak but significant correlation between exacerbation frequency and HRV loads, suggesting that frequent exacerbators are more susceptible to respiratory viral infection or are less able to prevent viral replication. A proposed mechanism of increased viral susceptibility is the modulation of intracellular adhesion molecule (ICAM)-1 on respiratory epithelial cells. ICAM-1 has been shown to be upregulated in the bronchial mucosa of patients with chronic bronchitis [20], which may lead to increases in HRV infection in these patients.

The EXACT is a patient-reported outcome measure that allows the standardisation of exacerbation frequency, severity and duration [16]. Using the EXACT questionnaire, we have demonstrated that patients with HRV at the time of sampling have higher EXACT scores than those without HRV, suggesting that exacerbations associated with HRV infection are more severe. EXACT scores could be used to assess exacerbation severity in future trials of antiviral therapy at COPD exacerbation. However, this scarcely reaches statistical significance and so future studies or larger study numbers may assist in making definitive conclusions.

A novel aspect of this study is that we assessed HRV load through the whole time-course of a naturally occurring exacerbation. To our knowledge, there are no previous data on the time-course of HRV infection in naturally occurring COPD exacerbations and its relationship to upper airway symptoms. We found HRV prevalence and load decreased from ExP until day 35, when no HRV was detected. There was a significant fall in the median HRV load from presentation to day 3 and from day 3 to day 7 . In our study, HRV load was highest at presentation, suggesting patients could have become infected a few days before presenting to the clinic. Colds precede exacerbation symptoms and in an experimental HRV study, HRV load was highest at day 5 post-inoculation [11], consistent with our findings.

The finding that HRV loads are high at COPD ExP is important. One of the many obstacles to the development of antiviral therapies for COPD exacerbations is that it is considered that patients are likely to present with symptoms and be prescribed therapy too late for the antiviral to have an effect. These data, however, show that HRV load is still high when patients present to the clinic, suggesting that viral replication may be ongoing and, therefore, antiviral therapy may be effective at this time-point. This highlights the unmet need for rapid development of antiviral therapies for the treatment of COPD exacerbations, as patients have high HRV loads even at exacerbation presentation.

We also studied co-infection with HRV and airway bacteria in patients throughout the time-course of the exacerbation, and found an association between initial HRV infection and secondary bacterial infection. A small number of studies have considered co-infection, such as the interaction of Haemophilus influenzae and HRV, showing that H. influenzae load, determined by culture, was markedly increased in the presence of HRV compared with cases without HRV [21]. Furthermore, MALLIA et al. [22], in a study of COPD patients experimentally infected with HRV, reported secondary bacterial infection in $60 \%$ of subjects after the initial inoculation, with bacterial load peaking on day 15. In our patients who were negative for bacteria at exacerbation presentation, $73 \%$ of samples were positive by day 14 and the bacterial load increased significantly by this time-point. This supports the concept of a direct link between HRV infection and secondary bacterial infection. In patients who were positive for bacteria at presentation, the load decreased significantly by day 7 , although there was a nonsignificant increase by day 14 . This increase at day 14 may 
possibly be due to the cessation of antibiotic therapy, although the increase in bacterial load in samples negative at presentation but positive at day 14, after an HRV infection, suggests that there may be a genuine link between initial HRV infection and secondary bacterial infection.

The fact that exacerbations that were bacterium-negative at ExP but became positive by day 14 were treated with antibiotics suggests that in exacerbations where an initial viral infection leads to a secondary bacterial infection, antiviral therapy may be more effective than antibiotics; however, antibiotics may be more relevant during the latter part of the exacerbation, when a secondary bacterial infection may develop.

There were very few patients that were not on ICS treatment and, therefore, no clear conclusions can be made about the effect of this treatment on either viral or bacterial loads.

The COPD patients were still symptomatic at day 14, when bacterial load peaked, and reported dyspnoea, cough, and changes in sputum volume and purulence, suggesting the increase in airway bacterial infection at day 14 is of clinical relevance. Patients hospitalised due to exacerbations have more marked lung function impairment and increased length of stay in the context of viral and bacterial co-infection [23]. Secondary bacterial infection may also play a part in exacerbation recurrence [13] and further studies are required to assess the longer term effects of these key findings.

There have been other studies investigating co-infection of viruses and bacteria at COPD exacerbation; however, they have found lower incidence of co-infection than our study, which may be due to the larger number of samples collected from patients during each exacerbation [23, 24]. A study in 2006 performed by PAPI et al. [23], where one sample was taken at each exacerbation, showed viral and bacterial co-infection in $25 \%$ of samples. HutCHINSON et al. [24] collected two samples during exacerbation and reported that $36 \%$ of exacerbations in which a virus was detected at onset developed a secondary bacterial infection over the following 7 days and overall, $78 \%$ of exacerbations in which $H$. influenzae was isolated in the first 5 days after onset were preceded by viral symptoms. In our study, we collected multiple samples during exacerbations and detected a higher incidence of co-infection than the studies mentioned above, which indicates that repeated sampling over the duration of an exacerbation is more likely to identify the presence of co-infection.

This study was limited to HRV infection and although other viruses have been studied at COPD exacerbation, HRV has been shown to be the most commonly detected [8]. Similarly, this study was limited to the commonest typical airway bacteria detected at COPD exacerbation, although it is unlikely that bacteria other than these three, play a significant role in the aetiology of community exacerbations [25].

In conclusion, this study of quantitative viral loads shows that HRV infection is associated with upper airway symptoms, typical airway bacteria and patient-reported outcomes in natural COPD exacerbations. We have also shown that patients with a history of frequent exacerbations are more susceptible to HRV infection. Secondary bacterial infection is common after HRV infection, and has important implications in terms of therapy and exacerbation recurrence. Treating respiratory viral infections in patients with COPD may therefore be key to reducing exacerbation frequency. Thus, there is an unmet need for rapid development of therapeutic targets for the prevention and treatment of respiratory viral infection in COPD patients.

\section{Acknowledgements}

The authors wish to thank the UK Medical Research Council for funding the London COPD Cohort. We wish to thank N. Bartlett (Imperial College London, London, UK) for his invaluable assistance in the HRV qPCR set-up. We are thankful to all patients of the London COPD Cohort for dedicating their time and energy making this study possible.

\section{References}

1 Lozano R, Naghavi M, Foreman K, et al. Global and regional mortality from 235 causes of death for 20 age groups in 1990 and 2010: a systematic analysis for the Global Burden of Disease Study 2010. Lancet 2012; 380: 2095-2128. Singanayagam A, Joshi PV, Mallia P, et al. Viruses exacerbating chronic pulmonary disease: the role of immune modulation. BMC Med 2012; 10: 27.

3 Wedzicha JA, Seemungal TAR. COPD exacerbations: defining their cause and prevention. Lancet 2007; 370: 786-796.

4 Seemungal TA, Donaldson GC, Paul EA, et al. Effect of exacerbation on quality of life in patients with chronic obstructive pulmonary disease. Am J Respir Crit Care Med 1998; 157: 1418-1422.

5 Pauwels RA, Buist AS, Calverley PM, et al. Global strategy for the diagnosis, management, and prevention of chronic obstructive pulmonary disease. NHLBI/WHO Global Initiative for Chronic Obstructive Lung Disease (GOLD) Workshop summary. Am J Respir Crit Care Med 2001; 163: 1256-1276.

6 Donaldson GC, Seemungal TAR, Bhowmik A, et al. Relationship between exacerbation frequency and lung function decline in chronic obstructive pulmonary disease. Thorax 2002; 57: 847-852.

7 Soler-Cataluña JJ, Martínez-García MA, Román Sánchez P, et al. Severe acute exacerbations and mortality in patients with chronic obstructive pulmonary disease. Thorax 2005; 60: 925-931.

8 Seemungal T, Harper-Owen R, Bhowmik A, et al. Respiratory viruses, symptoms, and inflammatory markers in acute exacerbations and stable chronic obstructive pulmonary disease. Am J Respir Crit Care Med 2001; 164: $1618-1623$. 
Seemungal TA, Harper-Owen R, Bhowmik A, et al. Detection of rhinovirus in induced sputum at exacerbation of chronic obstructive pulmonary disease. Eur Respir J 2000; 16: 677-683.

10 Kurai D, Saraya T, Ishii H, et al. Virus-induced exacerbations in asthma and COPD. Front Microbiol $2013 ; 4: 293$.

11 Mallia P, Message SD, Gielen V, et al. Experimental rhinovirus infection as a human model of chronic obstructive pulmonary disease exacerbation. Am J Respir Crit Care Med 2011; 183: 734-742.

12 Quint JK, Donaldson GC, Goldring JJP, et al. Serum IP-10 as a biomarker of human rhinovirus infection at exacerbation of COPD. Chest 2010; 137: 812-822.

13 Hurst JR, Donaldson GC, Quint JK, et al. Temporal clustering of exacerbations in chronic obstructive pulmonary disease. Am J Respir Crit Care Med 2009; 179: 369-374.

14 Chomczynski P, Sacchi N. Single-step method of RNA isolation by acid guanidinium thiocyanate-phenolchloroform extraction. Anal Biochem 1987; 162: 156-159.

15 Garcha DS, Thurston SJ, Patel ARC, et al. Changes in prevalence and load of airway bacteria using quantitative PCR in stable and exacerbated COPD. Thorax 2012; 67: 1075-1080.

16 Leidy NK, Wilcox TK, Jones PW, et al. Standardizing measurement of chronic obstructive pulmonary disease exacerbations. Reliability and validity of a patient-reported diary. Am J Respir Crit Care Med 2011; 183: 323-329.

17 Friedlander SL, Busse WW. The role of rhinovirus in asthma exacerbations. J Allergy Clin Immunol 2005; 116: 267-273.

18 Grünberg K, Timmers MC, de Klerk EP, et al. Experimental rhinovirus 16 infection causes variable airway obstruction in subjects with atopic asthma. Am J Respir Crit Care Med 1999; 160: 1375-1380.

19 Hurst JR, Donaldson GC, Wilkinson TMA, et al. Epidemiological relationships between the common cold and exacerbation frequency in COPD. Eur Respir J 2005; 26: 846-852.

20 Di Stefano A, Maestrelli P, Roggeri A, et al. Upregulation of adhesion molecules in the bronchial mucosa of subjects with chronic obstructive bronchitis. Am J Respir Crit Care Med 1994; 149: 803-810.

21 Wilkinson TMA, Hurst JR, Perera WR, et al. Effect of interactions between lower airway bacterial and rhinoviral infection in exacerbations of COPD. Chest 2006; 129: 317-324.

22 Mallia P, Footitt J, Sotero R, et al. Rhinovirus infection induces degradation of antimicrobial peptides and secondary bacterial infection in chronic obstructive pulmonary disease. Am J Respir Crit Care Med 2012; 186: 1117-1124.

23 Papi A, Bellettato CM, Braccioni F, et al. Infections and airway inflammation in chronic obstructive pulmonary disease severe exacerbations. Am J Respir Crit Care Med 2006; 173: 1114-1121.

24 Hutchinson AF, Ghimire AK, Thompson MA, et al. A community-based, time-matched, case-control study of respiratory viruses and exacerbations of COPD. Respir Med 2007; 101: 2472-2481.

25 White AJ, Gompertz S, Bayley DL, et al. Resolution of bronchial inflammation is related to bacterial eradication following treatment of exacerbations of chronic bronchitis. Thorax 2003; 58: 680-685. 